\title{
Review
}

Acta Cytologica 2016;60:501-512

DOI: $10.1159 / 000450595$
Received: September 5, 2016

Accepted after revision: September 6, 2016

Published online: November 3, 2016

\section{Virtues and Weaknesses of DNA Methylation as a Test for Cervical Cancer Prevention}

\author{
Attila T. Lorincz \\ Centre for Cancer Prevention, Wolfson Institute of Preventive Medicine, Queen Mary University of London, \\ London, UK
}

\section{Key Words}

Epigenetics · DNA methylation · Cervical intraepithelial neoplasia · Cervical cancer - Human papillomavirus . Biomarkers - Triage - Diagnostics · Molecular signature · Classifier · Score

\section{Abstract}

Epigenetics is the study of heritable and non-heritable genetic coding that is additive to information contained within classical DNA base pair sequences. Differential methylation has a fundamental role in the development and outcome of malignancies, chronic and degenerative diseases and aging. DNA methylation can be measured accurately and easily via various molecular methods and has become a key technology for research and healthcare delivery, with immediate roles in the elucidation of disease natural history, diagnostics and drug discovery. This review focuses on cancers of the lower genital tract, for which the most epigenetic information exists. DNA methylation has been proposed as a triage for women infected with human papillomavirus (HPV) and may eventually directly complement or replace HPV screening as a one-step molecular diagnostic and prognostic test. Methylation of human genes is strongly associated with cervical intraepithelial neoplasia (CIN) and cancer. Of the more than 100 human methylation biomarker genes tested so far

\section{KARGER}

E-Mail karger@karger.com www.karger.com/acy

\section{C) 2016 The Author(s) \\ Published by S. Karger AG, Basel 0001-5547/16/0606-0501\$39.50/0}

This article is licensed under the Creative Commons AttributionNonCommercial-NoDerivatives 4.0 International License (CC BYNC-ND) (http://www.karger.com/Services/OpenAccessLicense) Usage and distribution for commercial purposes as well as any distribution of modified material requires written permission. in cervical tissue, close to 20 have been reported in different studies, and approximately 10 have been repeatedly shown to have elevated methylation in cervical cancers and highgrade CIN (CIN2 and CIN3), most prominently CADM1, EPB41L3, FAM19A4, MAL, miR-124, PAX1 and SOX1. Obtaining consistent performance data from the literature is quite difficult because most methylation studies used a variety of different assay methodologies and had incomplete and/or biased clinical specimen sets, varying assay thresholds and disparate target gene regions. There have been relatively few validation studies of DNA methylation biomarkers in large population-based screening studies, but an encouraging development more recently is the execution of well-designed studies to test the true performance of the markers in real-world settings. Methylation of HPV genes, especially HPV16, HPV18, HPV31, HPV33 and HPV45, in disease progression has been a major focus of research. Elevated methylation of the HPV16 L1 and L2 open reading frames, in particular, is associated with CIN2, CIN3 and invasive cancer. Essentially all cancers have high levels of methylation for human genes and for driver HPV types, which suggests that quantitative methylation tests may have utility in predicting CIN2 and CIN3 that are likely to progress. It is still early in the process of development of methylation biomarkers, but already they are showing strong promise as a universal and systematic approach to molecular triage, applicable to all 
cancers, not just cancer of the cervix. DNA methylation testing is better than HPV genotyping triage and is competitive with or complementary to other approaches such as cytology and p16 staining. Genome-wide studies are underway to systematically expand methylation classifier panels and find the best combinations of biomarkers. Methylation testing is likely to show big improvements in performance in the next 5 years.

(C) 2016 The Author(s)

Published by S. Karger AG, Basel

\section{Epigenetics}

A principal goal of epigenetics is to understand the molecular patterning controls that govern the decoding and flow of genetic information [1,2]. For example, a simple sequence of DNA nucleotides such as ACTGACTG embedded in a chromosome carries information that the cell may decode in different ways based on the associated context. The cell may use the information to make part of a protein, part of a regulatory or structural element or perhaps a silent spacer. If the sequence changes to ACCGACTG, the mutation from $\mathrm{T}$ to $\mathrm{C}$ may or may not lead to functionally different information in the cell, depending on how the sequence is decoded. Epigenetics relates to how a gene sequence at any particular chromosomal location may be decoded in different ways without recourse to nucleotide mutations. As we will see below, differential decoding can lead to profoundly altered outcomes such as a change from a normal to a cancerous cell. Epigenetic mechanisms play a dynamic role in the creation and development of the human body, maintenance of health, ageing and death $[1,2]$. In contrast to genetic traits, epigenetic patterns are rarely inherited by offspring in a Mendelian manner; rather, they accumulate and increase in complexity from relatively simple imprinted profiles that evolve actively during development. Although the vast majority of methylated $\mathrm{CpG}$ motifs are not inherited meiotically, they are transmitted mitotically through cell lineages with good fidelity.

Epigenetic patterns guide future developmental possibilities and lock differentiated tissues into given states. The processes are affected by the environment, which leads to some interesting consequences; for example, particular epigenetic patterns accumulate on DNA and proteins during embryogenesis and may be further modified over time in ways that are different for every individual. Detrimental exposure to carcinogens, a poor diet, stress, a lack of exercise, obesity, etc., result in disease-promoting patterns, while beneficial lifestyle factors and effective drugs may result in health-maintaining or homeostatic patterns. The patterns are fluid and evolve to represent the molecular history of exposures and events in the body. With new molecular assays, we are learning how to read these codes, a pathway of discovery likely to dramatically change prognostic medicine and provide much greater accuracy in the prediction of disease outcomes to the point of practical personalized medicine [1-3].

Epigenetic patterns dictate how and when given sets of genes are expressed or silenced in tissues. A certain pattern of methylation may support neuronal differentiation, while another may support carcinoma (fig. 1). An interesting aspect of epigenetics is that the patterns can change during life and, although they are quite stable once established, they are potentially reversible or modifiable by drugs. Some epigenetic drugs may allow a return to an earlier state of health, while other exposures may induce progression to worse disease. The epigenetic mechanism can be imagined as a conductor of the genetic orchestra, bringing out the artistic individuality of each played piece.

\section{The Interface of Epigenetics and Genetics}

The heart of the epigenetic mechanism is methylation patterning, which occurs on various macromolecules including DNA and proteins $[1,2]$. At its simplest, the chemistry of mammalian DNA methylation involves the enzymatic addition or removal of a methyl group $\left(\mathrm{CH}_{3}\right)$ on specific cytosine $(\mathrm{C})$ nucleotides in a DNA sequence. This results in an alteration of the local steric and hydrophobic properties of the DNA. The presence of one or a few methyl groups may interfere with binding of regulatory factors due to steric or electrostatic exclusion, or it may enhance other interactions due to newly conducive van der Waals surfaces. Many methyl groups on a given sequence will lead to substantially more hydrophobic stretches of DNA that can become locally condensed and less accessible to proteins in general. At extreme levels of methylation, long segments of DNA or entire chromosomes condense into heterochromatin and become predominantly transcriptionally inert. The overall effects of changes in DNA methylation lead to temporary or permanent masking or unmasking of genetic information represented by the affected sequences. Aberrant methylation has additional effects on DNA integrity during carcinogenesis. DNA instability leads to an accumulation of somatic mutations encompassing nucleotide changes and gene copy number variations due to indels, translocations, 
Fig. 1. Schematic representation of DNA methylation, somatic mutations and HPV infection events during the development of normal epithelial tissues and progression to cervical cancer. There are tens of thousands of DNA changes that occur during the process depicted in this example, most of which are methylation. Epigenetic events are highly complex and play an important role in both normal development and progression to cancer. Normal methylation activity is shown along the arrows by $\mathrm{CH}_{3}$ in green, while abnormal methylation is shown in red. Mutational events (mut) are shown as an averaged mutational burden estimated from exome-sequencing studies [Lau and Lorincz, in preparation], with the larger letters (mut) indicating more mutations during progression from CIN3 to cancer. The main steps of high-risk HPV (hrHPV) infection and phenotypic effects are shown by the hexagons with the letter $\mathrm{H}$ and the red arrows.

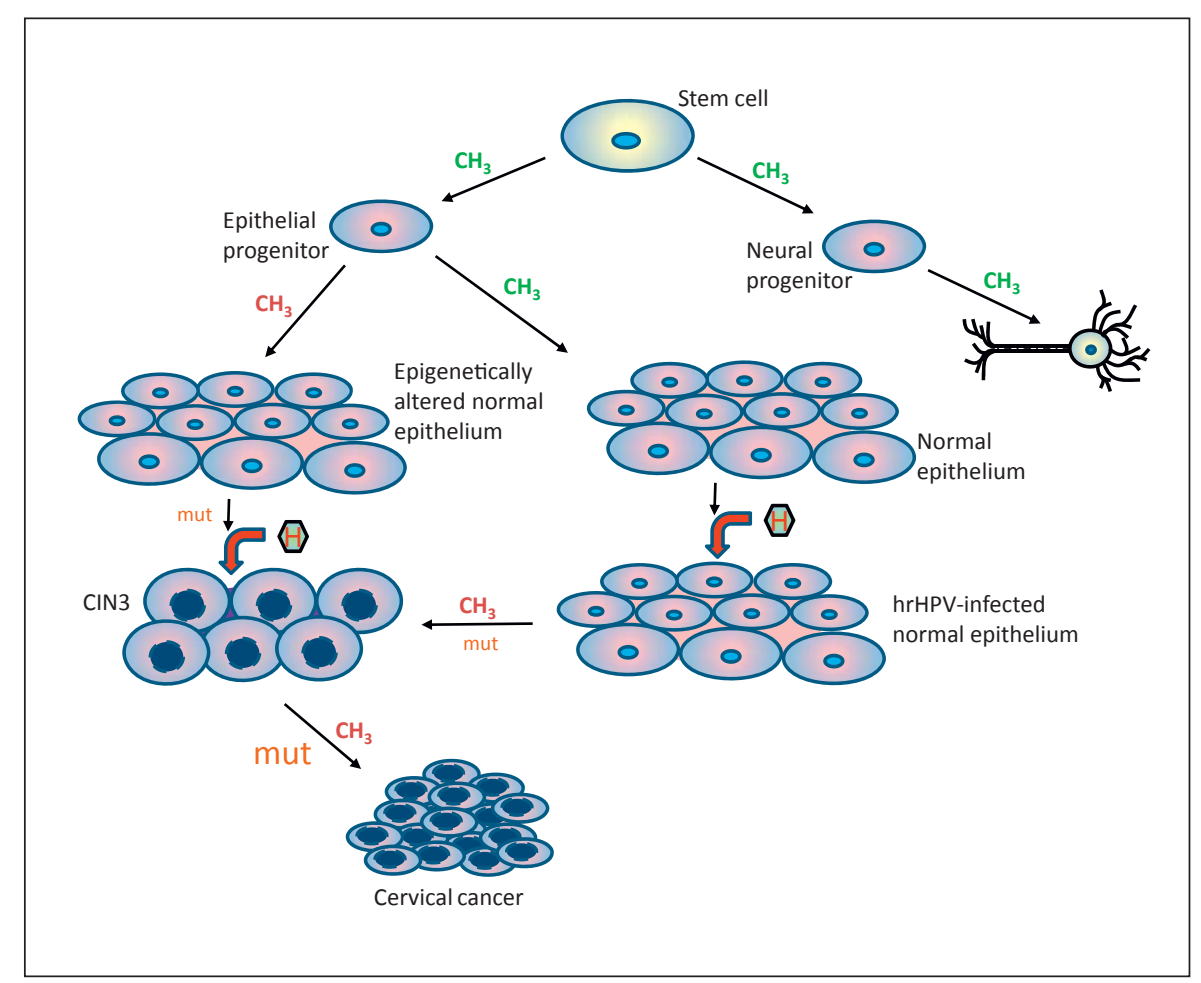

transpositions, amplications and loss of heterozygosity [1, $2,4]$. DNA methylation occurs most commonly on the 5 -position of the aromatic ring of a $\mathrm{C}$ that is immediately followed by a G; these sequences are called CpG sites or dyads because they form a reversed image on the antiparallel DNA strand. Methylated CpG are often located in $\mathrm{CpG}$ islands, which are regions of DNA, mostly in the vicinity of gene promoters or in gene bodies, that have a higher-than-expected representation of CpG motifs [5]. Much past research on DNA methylation has concentrated on CpG sites in these islands, but it is now clear that important methylation and demethylation events often occur on the edges of CpG islands (CpG shores, shelves or boundaries) or indeed completely away from the CpG islands [5-7]. Methylation also occurs on proteins, most prominently on histones that coat DNA in cell nuclei and form chromatin. CpG islands are often heavily methylated on their DNA and histones, except in regions where there are active gene promoters. It is for this reason that methylation of tumour suppressor gene promoters is so important - given enough methyl groups, the gene is silenced and has an effect analogous to a disabling Watson-Crick mutation or indel $[1,2,5]$. DNA and protein methylation work in concert to reinforce the overall patterns that govern decoding of genetic information.

DNA Methylation and Cervical Cancer Prevention
Given its biological importance, it is not surprising that DNA methylation is tightly controlled by specific enzymes (DNA methyl transferases) and regulatory factors, which are in turn controlled by the innate system circuitry of the tissue $[1,2,4]$. Methylation command systems have a window to the outside world, and external stimuli are allowed to impact and guide the patterns that develop. The epigenetic-environmental interface is part of a natural system that exists for the purpose of providing a more responsive and dynamic somatic palette than available from chance accumulation of Watson-Crick-type nucleotide mutations. Mutations that occur in germ cells can result in an intergenerational evolutionary step, but it is obvious that this response rate is many orders of magnitude lower than the epigenetic response rate. Of course, since carcinogenesis in the soma is a dead-end pathway, the build-up of mutational and epi-mutational events during disease progression does not noticeably impact the intergenerational flow of coding information. A key difference between epigenetic change and classical Watson-Crick mutations is that methylation changes are, at least in principle, more easily reversible, a feature that gives hope for future epi-reversals of minimally genetically damaged cancers. In other words, as long as the cancer has not festered too long and developed huge num- 
bers of somatic mutations, it could be induced to differentiate into a permanently quiescent tissue by targeted epigenetic drugs.

Measurable methylation pattern change in humans can be quite rapid, taking only a few months; hence, it is a deep reservoir for discovery of biomarkers that precede or evolve with disease $[8,9]$. Epigenetic biomarkers are especially important in complex multi-gene diseases such as common cancers, and epigenetic changes are much more frequent than genetic changes. The study of DNA methylation in particular is producing a huge number of interesting biomarkers. Although there are many diverse aspects to methylation, the translational studies usually focus on CpG patterns. DNA methylation is a mitotically transmitted epigenetic motif that can be measured with good accuracy in tissue biopsies, exfoliated cells, blood and other fluids and can be related to exact physical locations in the genome; this feature lends itself more readily to medical diagnostics. Clinically relevant methylation changes are known in many human cancers such as cervix, prostate, breast, colon, bladder, stomach, oesophagus and lung cancers [1, 10-12]. Differential methylation may have a central role in the development and outcome of most if not all human malignancies. The advent of accurate quantitative assays, including epigenome-wide deep sequencing, holds great promise for biomarker and drug discovery and the implementation of routine molecular clinical testing.

\section{DNA Methylation and Cervical Cancer}

Changes in DNA methylation are central to most cancers, including genital tract cancers. The changes cause defective gene expression, genetic instability through faulty condensation of chromosomes, and silencing of mobile DNAs such as jumping genes (transposons) and viruses. Attempted silencing of mobile DNA can spur molecular evolution as variants of the targeted DNA escape repression, which adds to host genetic instability. Methylation mechanisms can also amplify the effects of host mutations and lead to pre-cancers and cancers with relatively few detectable relevant genetic changes. Genome-wide studies of cancers generally show thousands of host somatic mutations or polymorphisms, but most changes have no significant associations or have quite small effect sizes. Much causal molecular pathway information seems to be missing or hidden in an excess of incidental mutations $[13,14]$, suggesting that key disease progression drivers may often be epigenetic in origin.
From a global perspective, cervical cancer was one of the most important cancers in women before the advent of widespread cytological screening; unfortunately, it is still among the most common cancers in many developing countries due to ineffective control measures. GLOBOCAN [15] data show an estimated 528,000 cases and 266,000 deaths worldwide due to cervical cancer, of which 83,000 cases and 35,000 deaths occurred in more developed regions and 445,000 cases and 230,000 deaths occurred in less developed regions. Papanicolaou (Pap) cytology screening programs detect most cervical intraepithelial neoplasias (CIN) with a potential to transform into malignancy and for which treatment may prevent the cancer. Unfortunately, the Pap test is difficult to implement and retain at high quality, especially in underdeveloped countries [16]. Numerous studies over the last 20 years have shown that even high-quality Pap cytology may miss $30 \%$ or more of high-grade CIN (CIN2 and CIN3) and invasive cancers [17-20]. Pap screening has been successful because it is repeated frequently over the lifetime of a woman.

Human papillomavirus DNA testing is more sensitive but less specific than Pap cytology [20-22]. The large majority of HPV infections become undetectable within a few years, and such transient infections are not associated with progression to cancer [21]. If performed at similar intervals, HPV testing produces positive results much more often in women who do not have CIN2 or CIN3 than does cytology testing; the medical community has struggled with this fact since the introduction of HPV DNA testing $[21,22]$.

\section{New Molecular Triage Tests for HPV-Positive Women}

It seems increasingly likely that HPV testing will eventually replace Pap cytology in most parts of the world [18, $21,22]$. The relatively low specificity of HPV DNA testing is slowing progress. Finding a better triage test for HPVinfected patients remains an important goal. Of greater importance are accurate molecular prognostic classifiers for people with hrHPV-positive (hrHPV+) test results, which could be done on the screening specimen and would reflexively indicate the future risk of progression. The ability to accurately tell whether the HPV infection will become a CIN3 or disappear would radically transform screening programs. The results would be reduced testing, lower costs, fewer overtreatments and less anxiety; this process may eventually eliminate cytology in cervical cancer screening. 
With high anticipated volumes of HPV testing, the impact of small differences in assay performance are greatly magnified, and at a population level there is a large cost to pursuing a testing strategy with an overall lower specificity. There are many current triage tests for hrHPV+ people, including cytology, immunostaining for p16 and Ki-67 and genotyping for HPV16, HPV18, HPV33 and HPV45 or combinations [17, 23-26]. Only genotyping has the benefit of a fully integrated molecular test, although merely differentiating among high-risk versus medium-risk HPV types adds relatively little of clinical value $[18,24,25,27]$. Numerically, most cervical HPV infections are of medium risk, which furthermore represents a diverse group, and they cannot be ignored because these types lead to a lot of cases of CIN3 and cancer [21, 24-29].

A new and promising triage for hrHPV+ women is DNA methylation testing $[1,8,10,17,27,28,30]$. Methylation measurement can be done as a simple reflex to the original screening specimen. The sample for the test can be placed in a transport liquid or mailed to the lab as a dry swab, eliminating the need for expensive and inconvenient transport media required for the preservation of morphology. There are many different molecular methodologies for DNA methylation testing. The most common is quantitative methylation-specific PCR (QMSP) [31]. Some studies have used pyrosequencing because it can be more accurately correlated to an absolute level of methylation, usually expressed as a simple percentage or proportion [8]. An older and almost obsolete method is bisulphite sequencing. The method gives good details of methylation variation on individual strands of DNA but is labour intensive and involves a potentially biasing cloning step [32]. More recently, methylation testing has moved into the genome-wide era with various chip-based and massively parallel deep-sequencing approaches [31].

\section{DNA Methylation Testing: Viral or Host Targets?}

Regardless of the methodology, DNA methylation assays have 3 basic target sequence designs that interrogate differential methylated CpG patterns on HPV genomes, human genomes or a combination of HPV and human DNA. It is not obvious which of these designs will produce the best classifiers going forward. Methylation assessment of both HPV and human genes provides synergistic information, but the assay design is slightly more complex [32-34]. The combination assay may have a greater sensitivity for $\mathrm{CIN} 3$ and a better unbiased area

DNA Methylation and Cervical Cancer Prevention
(AUC) under the receiver operator characteristic curve [35]. Almost all of the cancers can be detected in exfoliated cell samples by any of the 3 approaches, but catching cancers is not as important as catching pre-cancers [10, 36]. The argument that an absence of detectable methylation in CIN2 and CIN3 identifies high-grade lesions that do not progress does postulate an interesting idea and if true would quickly revolutionize patient management strategies. However, the idea needs to be proven in large well-designed clinical studies of which there are none to date.

\section{HPV Genome Methylation}

Differential changes in HPV DNA methylation were first reported in HPV1a in 1984 [37]. Similarly to methylation patterns seen more recently in the genital hrHPV types, HPV1 genomes extracted from warts had high levels of methylation of the viral late regions and low levels in the upstream regulatory and early region [9]. Gross genomic methylation patterns in the genital hrHPV types are quite similar. HPV16 has many differentially methylated $\mathrm{CpG}$ sites, with increased methylation of many but not all CpG sites in the LI, L2 and E2 genes being strongly associated with cervical carcinogenesis (fig. 2) [9, 30, 38]. HPV 16 and HPV18 combined contribute to approximately $70 \%$ of cervical cancers, while HPV 31 and HPV 33 are among the next most prevalent types, causing another $8 \%$ of cancers $[21,24]$. Expanding the methylation classifier to a panel of hrHPVs has been diagnostically worthwhile $[34,35]$. Accurate measurement of individual $\mathrm{CpG}$ DNA methylation on HPV genomes may be useful not only in epidemiological studies but also in following up HPV-infected women. A number of papers indicate that CpG methylation in HPV16 increases at a rate of about $0.5-0.7 \%$ per year while the infection remains persistent $[8,9]$. It is possible that this feature could be used to track infections in populations over time and to calculate ongoing risks of progression to CIN3 as methylation approaches levels characteristic of high-grade lesions. An interesting question is to determine whether some patients have a faster methylation rate than others and if so whether this may be linked to a higher risk of cancer.

\section{Human Genome Methylation}

More than 100 human genes have been proposed as possible methylation biomarkers of cervical cancer $[1,27$, $28,32,35,36,39-44]$. New genes are being discovered every year, increasingly by quasi-genomic approaches. So far, there does not seem to be any single gene that is sufficiently sensitive and specific for identifying CIN3, 
Fig. 2. Simplified representation of DNA methylation patterns during progression to cervical cancer. a Levels of DNA methylation across the genome of HPV 16, adapted from figure 1A of Mirabello et al. [9]. The lines represent the median percentage of methylation averaged across discrete sets of CpG sites in each HPV16 genomic region. HPV16 contains $113 \mathrm{CpG}$ sites (depending on the variant), and the levels depicted by the lines represent an approximate running average across the genome of HPV16, grouping adjacent (10-20) methylated CpGs. The levels of methylation of individual $\mathrm{CpG}$ sites are highly variable, with some CpG sites between other highly methylated sites showing no methylation. The bar at the bottom shows the various genomic regions, such as the upstream regulatory region (URR) and the early (E) and late (L) open reading frames of the HPV16 circular genome, which is shown here linearized in the URR for ease of visualization. b Median levels of DNA methylation of the human gene EPB41L3 and $2 \mathrm{CpG}$ sites in HPV16 L1 (6,367 and 6,389; genomic positions as shown in a) as a function of histopathological diagnosis. The lower and upper edges of the boxes represent the 25th and 75th percentiles, respectively, while the horizontal white lines show the median methylation values, and the 5 and 95\% values are shown by the lower and upper limits of the vertical lines, respectively. Adapted from figure 1 of Louvanto et al. [10]. CIN grades 1, 2 and 3 are represented by CIN1, CIN2 and CIN3, respectively. Cervical cancer is shown by SCC and cervical adenocarcinoma by ADC.

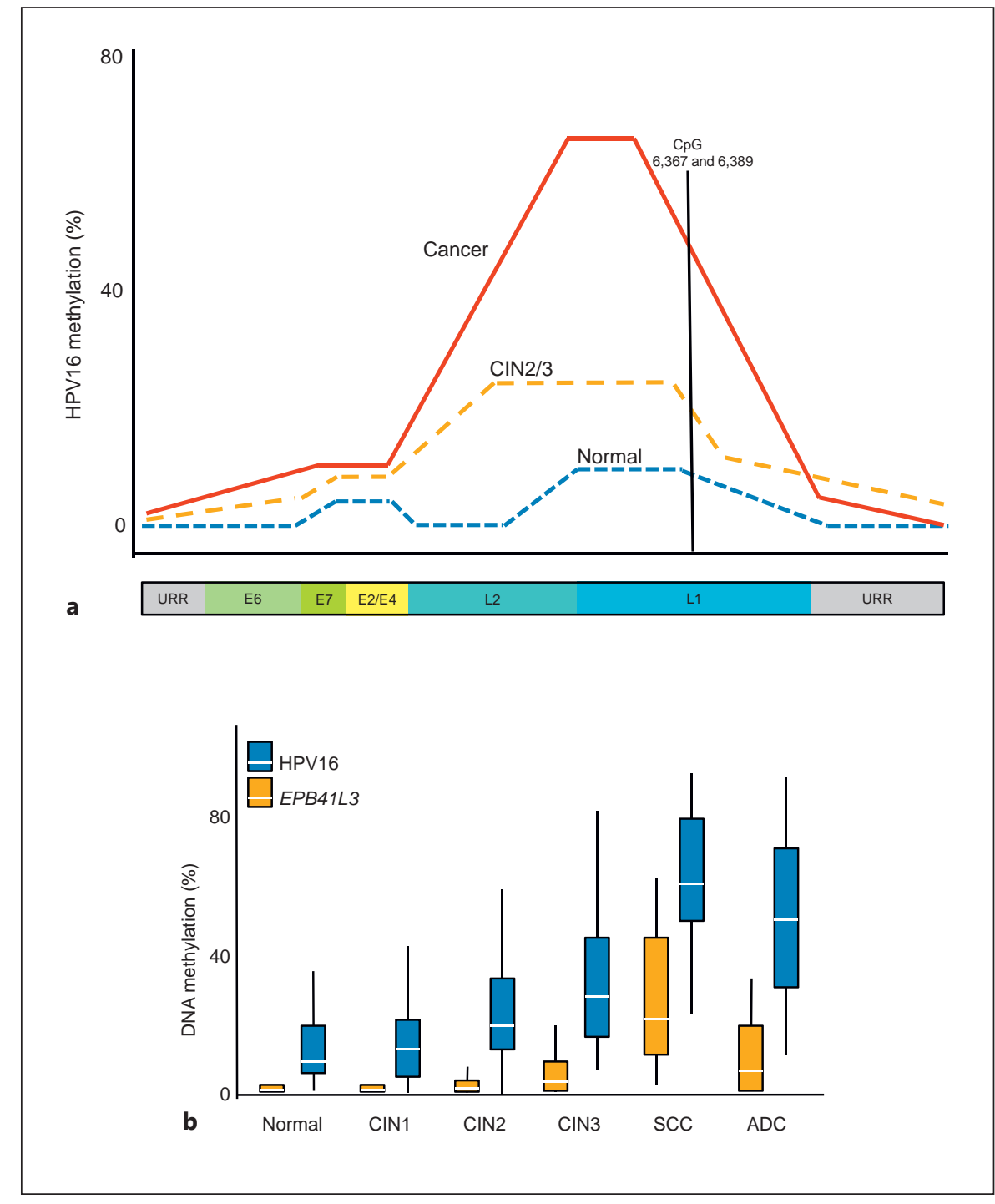

but some panels of genes look quite promising. Many alternative biomarker combinations can be constructed, and there are few overlaps of genes in many of the welldescribed panels. A plausible explanation for the abundance of riches is that aberrant methylation is an extensive and pervasive phenomenon in carcinogenesis, and it is practical to compose varied classifier panels from many different pathways to achieve similar if not identical triage possibilities. Table 1 shows a systematic review of the performance of human and HPV gene classifiers for detecting CIN2, CIN3 and cancer in 19 studies published since 2011 that met certain quality criteria as listed.

A pair of genes with extensive evidence of good performance in the scientific literature are MAL and CADM1. A combination QMSP test for these two genes in a set of specimens of hrHPV+ women from a screening population with a high-grade CIN and cancer (collectively CIN2+) endpoint gave a sensitivity of $68 \%$ (95\% CI 50$81 \%)$ and a specificity of $75 \%(95 \%$ CI $70-80 \%)$ at a selected cut-off, compatible with greater than $70 \%$ specificity. At another cut-off (table 1), the sensitivity of CADM1/ $M A L$ was $84 \%$ (95\% CI 72-93\%), the specificity was $52 \%$ (95\% CI 48-57\%), and the positive predictive value (PPV) was $25 \%$ (95\% CI 17-32\%), with an AUC of 0.72 [40]. In the same set of women, the triage sensitivity and specificity values for cytology were $66 \%$ (95\% CI 50-79\%) and 79\% (95\% CI 74-83\%), respectively (table 1). Cytology combined with genotyping for HPV16 and HPV18 had a sensitivity of $84 \%$ (95\% CI $72-93 \%)$ and a specificity of $54 \%$ (95\% CI 47-59\%). 
Table 1. Performance characteristics of selected DNA methylation studies in exfoliated cervical cell specimens for a high-grade CIN and cancer histopathological endpoint

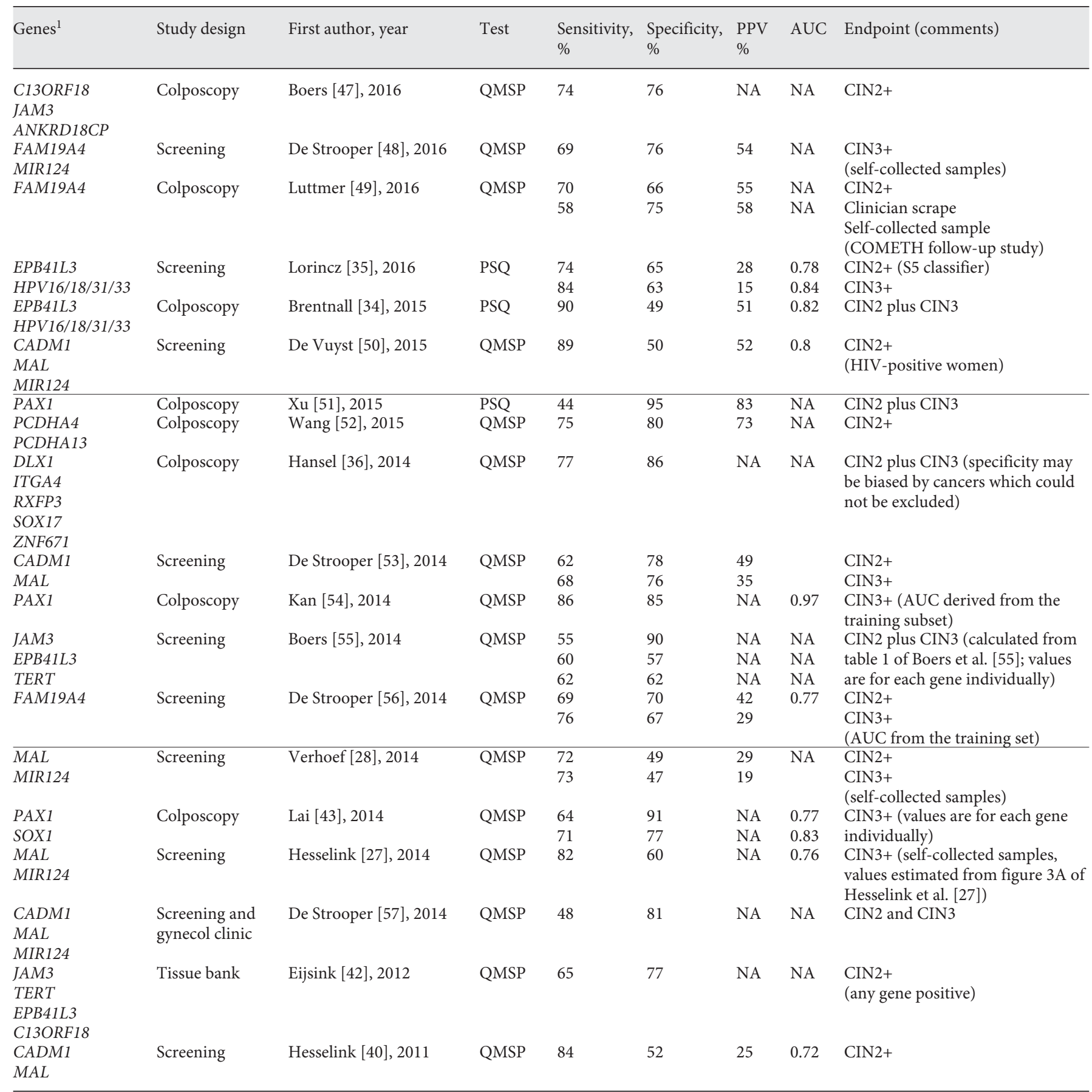

Included are relevant studies published in English that were indexed in PubMed. Studies that did not meet the following criteria were excluded: used exfoliated cervical cell specimens, had an endpoint of at least 20 cases of CIN2/3 diagnosed on histopathology, were unrestricted to particular hrHPV genotypes, provided data for sensitivity and specificity or allowed these to be calculated, cancers were present as a relatively normal subset of the sampling fraction (e.g. if cancers were more than $10 \%$ of CIN2/3 and cancers could not be excluded, then all data were excluded due to the risk of spectrum bias), and the marker reached a sensitivity of at least $40 \%$. In the study by Hansel et al. [36], relevant sensitivity for CIN2+ was provided; however, the provided specificity may be biased due to enrichment for cancers which could not be removed from the published data. CIN2+ = A combination group consisting of CIN2, CIN3 and cancers in a realistic sampling fraction (similarly, CIN3+ is CIN3 plus cancer); PPV = positive predictive value; AUC = area under the curve; QMSP = quantitative methylation-specific PCR; PSQ = pyrosequencing; NA = not available or not applicable due to spectrum bias. ${ }^{1}$ The combination tests used any gene marker positive unless noted otherwise.

DNA Methylation and Cervical Cancer Prevention
Acta Cytologica 2016;60:501-512

DOI: $10.1159 / 000450595$ 
In a self-sampling study, DNA methylation testing for $M A L$ and $m i R-124$ as a triage for screening program-noncompliant women who tested positive for HPV on selfcollected specimens showed a similar performance versus cytology done in the clinic. The sensitivity for CIN2+ was $70.5 \%$ (95\% CI 66.1-75.0\%) for methylation triage and $70.8 \%$ (95\% CI 66.1-75.4\%) for cytology triage, respectively, while the PPV was significantly lower $(31.7 \%$, 95\% CI $26.3-37.1 \%, \mathrm{p}<0.001)$ for DNA methylation triage than for cytology triage (50.3\%, 95\% CI 42.3-58.4\%) [41].

There have been a number of studies of DNA methylation testing of the genes EPB41L3, JAM3, TERT and C13ORF18; a combination of these genes gave a sensitivity of $65 \%$ and a specificity of $79 \%$ for detecting CIN2+ in an early study on a set of tissue bank convenience specimens (table 1) [42]. A QMSP study on the genes DLX1, ITGA4, RXFP3, SOX17 and ZNF671 showed 100\% (95\% CI 85.4-100\%) sensitivity for 19 invasive squamous cancers, while the sensitivity and specificity of a CIN2/3 (excludes cancer) endpoint were $43.1 \%$ (95\% CI 30.8-56\%) and $88.7 \%$ (95\% CI 82.1-93.5\%), respectively [36].

Studies on mainly Asian women employing QMSP tests for methylation of the genes PAX1 and SOX1 for the detection of CIN3+ have shown a promising performance. In a study of patients in a colposcopy population, the sensitivity of $P A X 1$ was $64 \%$ and for SOX1 it was $71 \%$, while the specificity was 91 and $77 \%$, respectively, and the AUC was 0.77 and 0.83 , respectively (table 1 ) [43]. Another methylated gene of interest is POU4F3, which has been tested in several studies from Asia [45]. Methylation levels of POU4F3 were assayed using QMSP on a set of 85 testing (verification) specimens at a pre-defined cut-off established in a larger training set of specimens. The sensitivity of the POU4F3 test for CIN3+ was $74 \%$, and the specificity was $89 \%$, with an AUC of 0.86 . These results are quite encouraging, and it will be interesting to see the validation results. A caveat of the POU4F3 study (excluded from table 1) is that the testing set was highly enriched for squamous cancers and adenocarcinomas, which may produce bias in the estimation of test performance. A study of SOX1 (with POU4F3 and some additional genes) suggests that methylation could be used to triage women with atypical glandular cells [46], with several potential genes giving similar results. The study included 55 women with atypical glandular cells on cytology, and the histological endpoint was 9 cases of CIN3+ (1 adenocarcinoma and 1 squamous cell carcinoma). Interestingly, the results showed that the best gene, i.e. SOX1, had a sensitivity of $100 \%$ (95\% CI $59-100 \%$ ), a specificity of $67 \%$ (95\% CI $52-80 \%$ ) and an AUC of 0.83 compared to $57 \%$
(95\% CI 18-90\%), 75\% (95\% CI 60-85\%) and 0.66, respectively, for HPV DNA testing.

Some of the more recent methylation studies since 2014 on screening and colposcopy populations had better designs and larger sample sizes, and sometimes they also had distinct training and validation phases. These studies therefore may give more realistic assessments of DNA methylation classifier performance [47-57]. The studies showed sensitivity for CIN2+ or CIN3+ to be in the range of $69-74 \%$ for clinician-collected specimens, while the specificity ranged from 66 to $76 \%$.

\section{Combination HPV and Host DNA Testing}

Two papers published simultaneously from different teams showed that a combination of methylation measurements of either DAPK1 or EPB41L3 in combination with methylation of HPV16, HPV18, HPV31 or HPV45 provides good triage for women with hrHPV+ test results [32-35]. The study with the DAPK1-HPV combination on samples from a US colposcopy population, that was enriched with additional cancers from Norway, gave a sensitivity of $80 \%$ and a specificity of $89 \%$ for detecting CIN2+. In comparison, the study with the EPB41L3-HPV combination on a UK colposcopy population (not enriched for cancers) gave a sensitivity of $90 \%$, a specificity of $49 \%$, a PPV of $51 \%$ and an AUC of 0.82 [32-34]. The EPB41L3-HPV gene combination (also called the S5 classifier) was validated in a separate large set of hrHPV+ women from a screening population in the UK and gave a sensitivity of $74 \%$ (95\% CI 59-85\%), a specificity of $65 \%$ (95\% CI 60-70\%) and an AUC of 0.78 for CIN2+, while for CIN3 + the sensitivity was $84 \%$ (95\% CI $62-94 \%$ ), the specificity was $63 \%$ (95\% CI 58-68\%), and the AUC was 0.84 (table 1) [35]. In comparison to HPV16 and HPV18 genotyping on the same samples, the S5 classifier had a much better triage performance, giving a higher sensitivity and specificity $(\mathrm{p}<0.0001)$.

\section{Virtues and Limitations of DNA Methylation Testing}

DNA methylation classifiers are a work in progress. There are many options for improving the classifiers by finding better genes and combing them in more sophisticated weighting combinations. The current performance leaves much to be desired. While some studies have shown an impressive performance, with a sensitivity and specificity close to $100 \%$, this has been in the context of artificial diagnostic scenarios. In rigorous studies with more formal training and validation designs, the sensitiv- 


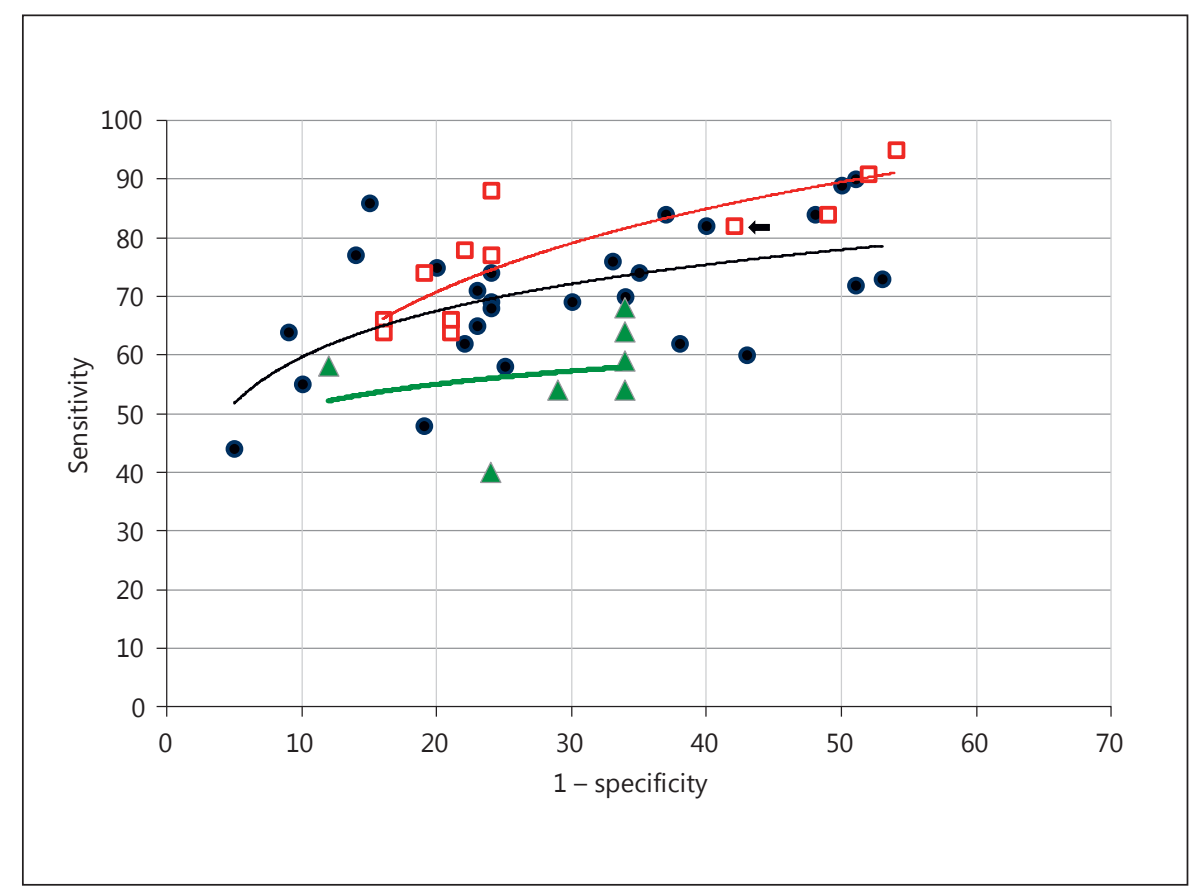

Fig. 3. Scatterplot of DNA methylation studies in table 1 (circles) showing the data in a receiver operator characteristic format, plotting sensitivity ( $\mathrm{y}$-axis) vs. 1 - specificity ( $\mathrm{x}$-axis). The figure plots methylation data for both CIN2+ and CIN3+ endpoints with all genes combined or individually, when available. In some studies, both $\mathrm{CIN} 2+$ and $\mathrm{CIN} 3+$ data were given, thus the graph presents some methylation data as multiply counted, for the individual values please refer to table 1 . The relationship between the $\mathrm{x}$ and $\mathrm{y}$ methylation data in the tabulated studies was fitted as a log model with the solid line representing the relationship of best fit. $\mathrm{y}=$ $11.387 \ln (\mathrm{x})+33.374 ; \mathrm{R}^{2}=0.3253$. Repeat cytology for triage of women with an earlier diagnosis of ASCUS or worse cytology in the meta-analysis of Arbyn et al. [20] showed a sensitivity of $82 \%$ and a specificity of $58 \%$ and is indicated by an open square and an arrow. The other open squares depict results obtained from cytology triage testing done in some of the studies shown in table 1 . Boers et al. [55]; endpoint CIN2+, sensitivity $=84$, specificity $=51$; endpoint CIN3+, sensitivity $=91$, specificity $=48$. De Strooper et al. [56]; endpoint CIN2+, sensitivity $=66$, specificity $=84$; endpoint CIN3+, sensitivity $=66$, specificity $=79$. De Strooper et al. [57]; endpoint CIN2/3, sensitivity $=77$, specificity $=76$; endpoint CIN3, sensitivity $=88$, specificity $=76$. De Strooper et al. [56]; endpoint CIN2+, sensitivity $=64$, specificity $=84$; endpoint $\mathrm{CIN} 3+$, sensitivity $=64$,

ity of methylation testing is usually less than $90 \%$, with an accompanying acceptable specificity and PPV which may range from 50 to $70 \%$ and from 20 to $50 \%$, respectively. Some critics may note that methylation assay performance characteristics are quite poor; however, it should be remembered that the data are for triage performance in enriched sets of women with on-going hrHPV infections and genetic and environmental risk factors of un- specificity $=79$. De Vuyst et al. [50]; endpoint CIN2+, sensitivity = 95 , specificity $=46$; endpoint $\operatorname{CIN} 3+$, sensitivity $=95$, specificity $=$ 46. Verhoef et al. [28]; endpoint CIN2+, sensitivity $=74$, specificity $=81$; endpoint CIN3+, sensitivity $=78$, specificity $=78$. Hesselink et al. [40]; endpoint CIN2+, sensitivity $=66$, specificity $=79$. The specificity estimates for CIN3 + contain additional uncertainty due to lack of information in some studies on whether the CIN2 were included or excluded from the normal/CIN1 category. The red line represents the relationship of best fit: $\mathrm{y}=20.46 \ln (\mathrm{x})+$ 9.4293; $\mathrm{R}^{2}=0.7022$. The relative performance of HPV16 and 18 genotyping for triage of CIN2+ or CIN3+ was obtained from some recent triage studies and is shown by the triangles. Hesselink et al. [27]; endpoint CIN3+, sensitivity $=58 \%$, specificity $=88 \%$. Verhoef et al. [28]; endpoint CIN2+, sensitivity $=59 \%$, specificity $=66 \%$; endpoint CIN3+, sensitivity $=68 \%$, specificity $=66 \%$. Lagos et al. [29]; endpoint CIN2+, sensitivity $=54 \%$, specificity $=66 \%$; endpoint CIN3+, sensitivity $=64 \%$, specificity $=66 \%$. DeVuyst et al. [50]; endpoint CIN2+ or CIN3+, sensitivity $=40 \%$, specificity $=$ $76 \%$. Lorincz et al. [35]; endpoint CIN2+, sensitivity $=54 \%$, specificity $=71 \%$. The model of best fit is shown by the green line and has the equation: $y=5.5308 \ln (x)+38.434 ; R^{2}=0.0565$. The study by Lagos et al. did not have associated methylation data.

known intensity and duration. In such settings, point specificity and PPV never approach what may be considered excellent values, and experts who understand the cervical cancer screening field would not expect current performance values of specificity and PPV close to $100 \%$. In comparison to DNA methylation testing, the use of cytology to triage screen-positive women has a similar but slightly better performance, especially when trying to 
maximize sensitivity (fig. 3). For the moment, in screening programs where cytology is already established and a switch to HPV screening is underway, it seems the better choice to designate cytology as the triage test for hrHPV+ women. However, in the case of new HPV screening programs that are thinking of establishing cytology as the triage test and now need to face the burdensome task of training cytologists and maintaining quality over long periods of time, careful consideration should be given to the alternative of DNA methylation triage.

It may be predicted that in risk-based algorithms that incorporate cumulative secularly integrated risk information the interval specificity and PPV values will be much higher. Most of the risk puzzle may be solved by delaying colposcopy until an optimal moment, which will become possible with an accurate understanding of the patient's comprehensive risk profile. Strong follow-up programs and the willingness of patients to wait under surveillance until a critical intervention point has been reached are other important components of such a follow-up algorithm. DNA methylation tests need further development and commercialization. Assays need to be simplified and automated. While these are limitations for near-term molecular assay simplification, automation and cost reductions are standard practice in today's technologically sophisticated world and merely represent short-term barriers that are easily and quickly overcome. It is likely to take longer for clinicians to become comfortable with the use of DNA methylation tests and to disseminate their use than for companies to simplify the technologies and make them available routinely.

\section{Future Perspectives}

DNA methylation assays are relatively simple, inexpensive and robust. In principle, hundreds of tests can be performed every week by average research laboratory technicians, and robotic equipment can increase the throughput to thousands of specimens per week. Improved methylation assays that have better or additional human genes and other hrHPV types should increase the AUC of the classifiers further. A triage AUC $>0.9$ may be within reach in a few years and is consistent with a sensitivity of $90 \%$ and a specificity of $\sim 80 \%$. Considering a combination reflex testing approach with hrHPV screening at a sensitivity and specificity of 95 and $90 \%$, respectively, and applying a reflex methylation triage with an AUC of 0.9 to the hrHPV positives, we could expect a final molecular screening algorithm sensitivity and speci- ficity of approximately 85 and 98\%, respectively, for CIN2/3 in the first round of screening. Close to $100 \%$ of the cervical cancers would be detected $[10,18,36]$. A way to improve on the sensitivity of $85 \%$ for CIN $2 / 3$ is to refer women who are hrHPV+ but methylation-negative to retesting for HPV in 1-2 years, which would identify women with persistent infection and reveal most of the remaining CIN2+ cases. DNA methylation assays have competitive performance versus other triage options today, while some realistic near-term improvements would place methylation testing at the forefront of reflex triage tests for hrHPV + women. In principle, DNA methylation testing could replace HPV DNA testing altogether, with just modest improvements in test technology. Overall, the performance of methylation assays may be substantially superior if the method can differentiate between CIN2/3 that progresses and lesions that do not. A combination of methylation biomarkers with somatic mutations identified by deep sequencing may produce hybrid classifier panels with additional prognostic features that could allow both certainty of event and estimated time to event calculations. We can expect to see many better assays and also commercially competing methylation assays in the near future.

\section{Acknowledgements}

I thank all of the participating patients in my studies. I am indebted to my work colleagues and collaborators whose roles in my studies were of profound importance. Particular thanks go to the staff of the Centre for Cancer Prevention, Wolfson Institute of Preventive Medicine, including Jack Cuzick, Peter Sasieni, Adam Brentnall, Amar Ahmad, Louise Cadman and Janet Austin. I also thank the current and past members of the Molecular Epidemiology Laboratory including Wai King Lau, Natasa Vasiljevic, Caroline Reuter, Dorota Scibior Bentkowska, Rhian Warman, Rawinder Banwait and Paul Carter. The unpublished DNA methylation systematic review and meta-analysis of Helen Kelley was of great value for this review. Interested parties may contact me or Helen for additional details of the review and characteristics of the data selection and mining. This work was supported by a Cancer Research UK program grant (No. C569/A10404). Funders had no role in the review design, collection, analysis, interpretation of data or writing of this review.

\section{Disclosure Statement}

There were no conflicts of interests of which the author was aware in the conduct of this review. The author did not receive any payments and does not anticipate any future payments, compensation, financial or beneficial considerations or favours for the conduct of the review or the writing of this paper. 


\section{References}

1 Lorincz AT: Cancer diagnostic classifiers based on quantitative DNA methylation. Expert Rev Mol Diagn 2014;14:293-305.

-2 Robertson KD: DNA methylation and human disease. Nat Rev Genet 2005;6:597-610.

- 3 Rasool M, Malik A, Naseer MI, Manan A, Ansari SA, Begum I, Qazi MH, Pushparaj PN, Abuzenadah AM, Al-Qahtani MH, Kamal MA, Pushparaj PN, Gan SH: The role of epigenetics in personalized medicine: challenges and opportunities. BMC Med Genomics 2015:8(suppl 1):S5.

-4 Liu S, Wang J, Su Y: Quantitative assessment of Tet-induced oxidation products of 5-methylcytosine in cellular and tissue DNA. Nucleic Acids Res 2013:41:6421-6429.

5 Illingworth RS, Bird AP: CpG islands - 'a rough guide'. FEBS Let 2009;583:1713-1720.

- 6 Kim JH, Dhanasekaran SM, Prensner JR, Cao X, Robinson D, Kalyana-Sundaram S, Huang C, Shankar S, Jing X, Iyer M, Hu M, Sam L, Grasso C, Maher CA, Palanisamy N, Mehra R, Kominsky HD, Siddiqui J, Yu J, Qin ZS, Chinnaiyan AM: Deep sequencing reveals distinct patterns of DNA methylation in prostate cancer. Genome Res 2011;21:1028-1041.

7 Bert SA, Robinson MD, Strbenac D, Statham AL, Song JZ, Hulf T, Sutherland RL, Coolen MW, Stirzaker C, Clark SJ: Regional activation of the cancer genome by long-range epigenetic remodelling. Cancer Cell 2013;23:922.

8 Lorincz AT, Brentnall AR, Vasiljević N, Scibior-Bentkowska D, Castanon A, Fiander A, Powell N, Tristram A, Cuzick J, Sasieni P: HPV16 L1 and L2 DNA methylation predicts high grade cervical intraepithelial neoplasia in women with mildly abnormal cervical cytology. Int J Cancer 2013;133:637-644.

-9 Mirabello L, Schiffman M, Ghosh A, Rodriguez AC, Vasiljevic N, Wentzensen N, Herrero R, Hildesheim A, Wacholder S, ScibiorBentkowska D, Burk RD, Lorincz AT: Elevated methylation of HPV16 DNA is associated with the development of high grade cervical intraepithelial neoplasia. Int J Cancer 2013 132:1412-1422.

10 Louvanto K, Franco EL, Ramanakumar AV, Vasiljević N, Scibior-Bentkowska D, Koushik A, Cuzick J, Coutlée F, Lorincz AT: Methylation of viral and host genes and severity of cervical lesions associated with human papillomavirus type 16. Int J Cancer 2015;136:E638E645.

$\$ 11$ Vasiljević N, Ahmad AS, Beesley C, Thorat MA, Fisher G, Berney DM, Møller H, Yu Y, Lu YJ, Cuzick J, Foster CS, Lorincz AT: 2013. Association between DNA methylation of $H S P B 1$ and death in low Gleason score prostate cancer. Prostate Cancer Prostatic Dis 2013; 16:35-40

12 Heyn H, Carmona FJ, Gomez A, Ferreira HJ, Bell JT, Sayols S, Ward K, Stefansson OA, Moran S, Sandoval J, Eyfjord JE, Spector TD, Esteller M: DNA methylation profiling in breast cancer discordant identical twins identifies DOK7 as a novel epigenetic biomarker. Carcinogenesis 2013;34:102-108.

13 Williams M, Werner B, Barnes CP, Graham TG, Sottoriva A: Identification of neutral tumor evolution across cancer types. Nat Genet 2016;48:238-244.

14 Martinez P, Timmer MR, Lau CT, Calpe S, Sancho-Serra MDC, Straub D, Baker AM, Meijer SL, ten Kate FJW, Mallant-Hent RC, Naber AHJ, van Oijen AHAM, Baak LC, Scholten P, Bohmer CJM, Fockens P, Bergman JGHM, Maley CC, Graham TA, Krishnadath KK: Dynamic clonal equilibrium and predetermined cancer risk in Barrett's esophagus. Nat Commun 2016;7:12158.

15 International Agency for Research on Cancer, World Health Organization: GLOBOCAN 2012. http://globocan.iarc.fr.

16 Lazcano-Ponce E, Lorincz AT, Cruz-Valdes A, Salmeron J, Uribe P, Velasco-Mondragón E, Hernandez Nevarez P, Diaz Acosta R, Hernández-Avila M: Self-collection of vaginal specimens for human papillomavirus testing in cervical cancer prevention (MARCH): a community-based randomised controlled trial. Lancet 2011;378:1868-1873.

17 Cuzick J, Bergeron C, von Knebel Doeberitz M, Gravitt P, Jeronimo J, Lorincz AT, Meijer CJLM, Sankaranarayanan R, Snijders PJF, Szarewski A: New technologies and procedures for cervical cancer screening. Vaccine 2012;30S:F107-F116.

18 Lorincz AT, Castanon A, Wey Lim AW, Sasieni P: New strategies for papillomavirusbased cervical screening. Womens Health 2013;9:443-452.

19 Ronco G, Dillner J, Elfstrom KM, Tunesi S, Snijders PJF, Arbyn M, Kitchener H, Segnan N, Gilham C, Giorgi-Rossi P, Berkhof J, Peto J, Meijer CJ: Efficacy of HPV-based screening for prevention of invasive cervical cancer: follow-up of four European randomised controlled trials. Lancet 2014;383:524-532.

20 Arbyn M, Buntinx F, Van Ranst M, Paraskevaidis E, Martin-Hirsch P, Dillner J: Virologic versus cytologic triage of women with equivocal pap smears: a meta analysis of the accuracy to detect high-grade intraeipthelial neoplasia. J Natl Cancer Inst 2004;96: 280-293.

21 Bosch FX, Lorincz A, Muñoz N, Meijer CJ, Shah KV: The causal relation between human papillomavirus and cervical cancer. J Clin Pathol 2002;55:244-265.

22 Dillner J, Reboli M, Birembaut P, Petry KU, Szarewski A, Munk C, de Sanjose S, Naucler P, Lloveras B, Kjaer S, Cuzick J, van Ballegooijen $\mathrm{M}$, Clavel C, Iftner T: Long term predictive values of cytology and human papillomavirus testing in cervical cancer screening: joint European cohort study. BMJ 2008; 337:a1754.

23 Carozzi F, Gillio-Tos A, Confortini M, Del Mistro A, Sani C, DeMarco L, Girlando S,
Rosso S, Naldoni C, Dalla Palma P, Zorzi M, Giorgi-Rossi P, Segnan N, Cuzick J, Ronco G: Risk of high-grade cervical intraepithelial neoplasia during follow-up in HPV-positive women according to baseline p16-INK4A results: a prospective analysis of a nested substudy of the NTCC randomised controlled trial. Lancet Oncol 2013;14:168-176.

24 Lorincz AT, Reid R, Jenson AB, Greenberg MD, Lancaster W, Kurman RJ: Human papillomavirus infection of the cervix: relative risk associations of 15 common anogenital types. Obstet Gynecol 1992;79:328-337.

25 Khan MJ, Castle PE, Lorincz AT, Wacholder S, Sherman M, Scott DR, Rush BB, Glass AG, Schiffman M: The elevated 10-year risk of cervical precancer and cancer in women with human papillomavirus (HPV) type 16 or 18 and the possible utility of type-specific HPV testing in clinical practice. J Natl Cancer Inst 2005;97:1072-1079.

26 Wright TC, Stoler MH, Behrens CM, Sharma A, Zhang G, Wright TL: Primary cervical cancer screening with human papillomavirus: end of study results from the ATHENA study using HPV as the first-line screening test. Gynecol Oncol 2015;136:189-197.

27 Hesselink AT, Heideman DAM, Steenbergen RDM, Gok M, van Kemenade FJ, Wilting SM, Berkhof J, Meijer CJLM, Snijders PJF: Methylation marker analysis of self-sampled cervico-vaginal lavage specimens to triage highrisk HPV-positive women for colposcopy. Int J Cancer 2014;135:880-886

28 Verhoef VMJ, Heideman DAM, van Kemenade FJ, Rozendaal L, Bosgraaf RP, Hesselink AT, Bekkers RLM, Massuger FAG, Steenbergen RDM, Snijders PJF, Berkhof, J, Meijer CJLM: Methylation marker analysis of HPV16/18 genotyping in high-risk HPV positive self-sampled specimens to identify women with high grade CIN or cervical cancer. Gynecol Oncol 2014;135:58-63.

-29 Lagos M, Van De Wyngard V, Poggi H, Cook P, Viviani P, Barriga MI, Pruyas M, Ferreccio C: HPV16/18 genotyping for the triage of HPV positive women in primary screening in Chile. Infect Agent Cancer 2015;10:43.

- 30 Vasiljevic N, Scibior-Bentkowska D, Brentnall A, Cuzick J, Lorincz A: A comparison of methylation levels in HPV18, HPV31 and HPV 33 genomes reveals similar associations with cervical precancers. J Clin Virol 2014;59: 161-166.

31 Laird PW: Principles and challenges of genome-wide DNA methylation analysis. Nat Rev Genet 2010;11:191-203.

32 Kalantari M, Osann K, Calleja-Macias IE, Kim S, Yan B, Jordan S, Chase DM, Tewari KS, Bernard HU: Methylation of human papillomavirus $16,18,31$, and $45 \mathrm{~L} 2$ and $\mathrm{L} 1$ genes and the cellular DAPK gene: considerations for use as biomarkers of the progression of cervical neoplasia. Virology 2014;448:314321.
DNA Methylation and Cervical Cancer Prevention
Acta Cytologica 2016;60:501-512 DOI: $10.1159 / 000450595$ 
- 33 Brentnall AR, Vasiljević N, Scibior-Bentkowska D, Cadman L, Austin J, Szarewski A, Cuzick J, Lorincz AT: A DNA methylation classifier of cervical pre-cancer based on human papillomavirus and human genes. Int $\mathrm{J}$ Cancer 2014;135:1425-1432.

- 34 Brentnall AR, Vasiljevic N, Scibior-Bentkowska D, Cadman L, Austin J, Cuzick J, Lorincz AT: DNA methylation assay for HPV 33 contributes independent triage information to HPV16, HPV18, HPV31, and EP$B 41 L 3$ for detecting cervical pre-cancer. Cancer Biomark 2015;15:669-675.

- 35 Lorincz AT, Brentnall AR, Scibior-Bentkowska D, Reuter C, Banwait R, Cadman L, Austin J, Cuzick J, Vasiljević N: Validation of a DNA methylation HPV triage classifier in a screening sample. Int J Cancer 2016;138:2745-2751.

- 36 Hansel A, Steinbach D, Greinke C, Schmitz M, Eiselt J, Scheungraber C, Gajda M, Hoyer $\mathrm{H}$, Runnenbaum IB, Durst M: A promising DNA methylation signature for the triage of high-risk human papillomavirus DNA-positive women. PLoS One 2014;9:e91905.

-37 Burnett ST, Sleeman J: Uneven distribution of methylation sites within the human papillomavirus la genome: possible relevance to viral gene expression. Nucleic Acids Res 1984; 12:8847-8860.

38 Wentzensen N, Sun C, Ghosh A, Kinney W, Mirabello L, Wacholder S, Shaber R, LaMere B, Clarke M, Lorincz AT, Castle PE, Schiffman M, Burk RD: Methylation of HPV18, HPV31, and HPV45 genomes and cervical intraepithelial neoplasia grade 3. J Natl Cancer Inst 2012;104:1738-1749.

-39 Vasiljevic N, Scibior-Bentkowska D, Brentnall AR, Cuzick J, Lorincz A: Credentialing of DNA methylation assays for human genes as diagnostic biomarkers of cervical intraepithelial neoplasia in high-risk HPV positive women. Gynecol Oncol 2014;132:709-714.

-40 Hesselink AT, Heideman DAM, Steenbergen RDM, Coupe VMH, Overmeer RM, Rijkaart D, Berkhof J, Meijer CJLM, Snijders PJF: Combined promoter methylation analysis of $C A D M 1$ and $M A L$ : an objective triage tool for high-risk human papillomavirus DNA-positive women. Clin Cancer Res 2011;17:24592465.

-41 Verhoef VM, Bosgraaf RP, van Kemenade FJ, Rozendaal L, Heideman DA, Hesselink AT, Bekkers RL, Steenbergen RD, Massuger LF, Melchers WJ, Bulten J, Overbeek LI, Berkhof J, Snijders PJ, Meijer CJ: Triage by methylation-marker testing versus cytology in women who test HPV-positive on self-collected cervicovaginal specimens (PROHTECT-3): a randomised controlled non-inferiority trial. Lancet Oncol 2014;15:315-322.

42 Eijsink JJH, Lendvai A, Deregowski V, Klip HG, Verpooten G, Dehaspe L, de Bock GH, Hollema H, van Criekinge W, Schuuring E, van der Zee AGJ, Wisman GBA: A four-gene methylation marker panel as triage test in high-risk human papillomavirus positive patients. Int J Cancer 2012;130:1861-1869.

43 Lai HC, Ou YC, Chen TC, Huang HJ, Cheng $\mathrm{YM}$, Chen $\mathrm{CH}$, Chu TY, Hsu ST, Liu CB, Hung YC, Wen KC, Yu MH, Wang K: PAX1/ SOX1 DNA methylation and cervical neoplasia detection: a Taiwanese Gynecologic Oncology Group (TGOG) study. Cancer Med 2014;3:1062-1074.

44 Wilhelm T: Phenotype prediction based on genome-wide DNA methylation data. BMC Bioinformatics 2014;15:193.

-45 Pun PB, Liao YP, Su PH, Wang HC, Chen YC, Hsu YW, Huang RL, Chang CC, Lai HC: Triage of high-risk human papillomavirus positive women by methylated POU4F3. Clin Epigenetics 2015;7:85.

46 Chang CC, Ou YC, Wang KL, Chang TC, Cheng YM, Chen CH, Chu TY, Hsu ST, Liou WS, Chang YY, Wu HH, Chen TH, Lai HC: Triage of atypical glandular cell by SOX1 and POU4F3 methylation: a Taiwanese Gynecologic Oncology Group (TGOG) study. PLoS One 2015;10:e128705.

47 Boers A, Wang R, van Leeuwen RW, Klip HG, de Bock GH, Hollema H, van Criekinge W, de Meyer T, Denil S, van der Zee AGJ, Schuuring E, Wisman GBA: Discovery of new methylation markers to improve screening for cervical intraepithelial neoplasia grade $2 / 3$. Clin Epigenetics 2016;8:29.

48 De Strooper LMA, Verhoef VMJ, Berkhof J, Hesselink AT, de Bruin HME, van Kemenade FJ, Bosgraaf RP, Bekkers RLM, Massuger LFAG, Melchers WJG, Steenbergen RDM, Snijders PJF, Meijer CJLM, Heideman DAM: Validation of the FAM19A4/mir124-2 DNA methylation test for both lavage- and brushbased self-samples to detect cervical (pre)cancer in HPV-positive women. Gynecol Oncol 2016;141:341-347.

-49 Luttmer R, De Strooper LMA, Dijkstra MG, Berkhof J, Snijders PJF, Steenbergen RDM, van Kemenade FJ, Rozendaal L, Helmerhorst TJM, Verheijn RHM, ter Harmsel WA, van Baal WM, Graziosi PGCM, Quint WGV, Spruijt JWM, van Dijken DKE, Heideman DAM, Meijer CJLM: FAM19A4 methylation analysis in self-samples compared with cervi- cal scrapes for detecting cervical (pre)cancer in HPV-positive women. Br J Canc 2016;115: 579-582.

50 De Vuyst H, Franceschi S, Plummer M, Mugo NR, Sakr SR, Meijer CJLM, Heideman DAM, Tenet V, Snijders PJF, Hesselink AT, Chung $\mathrm{MH}$ : Methylation levels of CADM1, MAL and MIR124-2 in cervical scrapes for triage of HIV-infected, high-risk HPV-positive women in Kenya. J Acquir Immune Defic Syndr 2015;70:311-318.

$51 \mathrm{Xu} \mathrm{J}, \mathrm{Xu}$ L, Yang B, Wang L, Lin X, Tu H: Assessing methylation status of $P A X 1$ in cervical scrapings as a novel diagnostic and predictive biomarker was closely related to screen cervical cancer. Int J Clin Exp Pathol 2015;8:16741681.

52 Wang KH, Lin CJ, Liu CJ, Liu DW, Huang RL, Ding DC, Weng CF, Chu TY: Global methylation silencing of clustered proto-cadherin genes in cervical cancer: serving as diagnostic markers comparable to HPV. Cancer Med 2015;4:43-55.

-53 De Strooper LMA, Hesselink AT, Berkhof J, Meijer CJLM, Snidjers PJF, Steenbergen RDM, Heideman DAM: Combined CADM1/ $M A L$ methylation and cytology testing for colposcopy triage of high-risk HPV-positive women. Cancer Epidemiol Biomarkers Prev 2014;23:1933-1937.

54 Kan YY, Liou YL, Wang HJ, Chen CY, Sung LC, Chang CF, Liao CI: PAXI methylation as a potential biomarker for cervical cancer screening. Int J Gynecol Cancer 2014;24:928934.

55 Boers A, Bosgraaf RP, van Leeuwen RW, Schuuring E, Heideman DAM, Massuger LFAG, Verhoef VMJ, Bulten J, Melchers, WJG, van der Zee AGJ, Bekkers RLM, Wisman GBA: DNA methylation analysis in selfsampled brush material as a triage test in hrHPV-positive women. Br J Cancer 2014; 111:1095-1101.

56 De Strooper LMA, Meijer CJLM, Berkhof J, Hesselink AT, Snijders PFJ, Steenbergen RDM, Heideman DAM: Methylation analysis of the FAM19A4 gene in cervical scrapes is highly efficient in detecting cervical carcinomas and advanced CIN2/3 lesions. Cancer Prev Res 2014;7:1251-1257.

57 De Strooper LMA, van Zummeren M, Steenbergen RDM, Bleeker MCG, Hesselink AT, Wisman GBA, Snijders PJF, Heideman DAM, Meijer CJLM: CADM1, MAL and miR124-2 methylation analysis in cervical scrapes to detect cervical and endometrial cancer. J Clin Pathol 2014;67:1067-1071. 